\title{
Purifying Immature Neurons from Differentiating Neural Stem Cell Progeny Using a Simple Shaking Method
}

\section{Hassan Azari' ${ }^{1-3 *}$, Sharareh Sharififar', Roya P Darioosh', Jeff M Fortin', Maryam Rahman ${ }^{1}$ and Brent A Reynolds ${ }^{1}$}

${ }^{1}$ Department of Neurosurgery, McKnight Brain Institute, University of Florida, Gainesville, FL, USA

${ }^{2}$ Neural Stem Cell and Regenerative Neuroscience Laboratory, Department of Anatomical Sciences, Shiraz University of Medical Sciences, Shiraz, Iran

${ }^{3}$ Neural Stem Cell and Regenerative Neuroscience Laboratory, Shiraz Stem Cell Institute, Shiraz University of Medical Sciences, Shiraz, Iran

\begin{abstract}
Objective: Enriched neuronal cell populations are valuable tools both for laboratory investigations and cell therapy applications. However, available cell purifying approaches demand costly equipment such as FACS or MACS that limits their universal accessibility. In this study, we developed an efficient method for purifying immature neuronal cells from differentiating neural stem cell (dNSC) progeny based on their differential substrate attachment properties without using any expensive cell separating tools.
\end{abstract}

Methods: Neural stem cells were harvested from the ganglionic eminence of embryonic day 14 mice brains using the neurosphere assay. Neurospheres were then dissociated into single cells and differentiated employing the neuroblast assay method. Following a brief trypsinization, the dNSC culture was gently shaken at $150 \mathrm{rpm}$ for $30 \mathrm{~min}$ to detach the top neuronal cell clusters from the underlying astrocytic cell monolayer. The neuronal purification yield, astrocyte contamination, and presence of dividing cells were compared to a MACS purification method using PSANCAM antibody.

Results: While a neuronal yield of $97.1 \pm 0.45 \%$ was achieved using MACS; it reached $97.9 \pm 0.6 \%$ using the shaking method that was not significantly different.On the other hand, the percentage of astrocytes in the MACS approach was $1.18 \pm 0.15 \%$, but it significantly decreased to $0.6 \pm 0.15 \%$ using the shaking method. Moreover, $4.41 \pm 0.23 \%$ and $5.3 \pm 0.4 \%$ of the isolated cells in the MACS and shaking methods, respectively, were Ki-67 immunoreactive dividing cells, of which $97.34 \pm 1.6 \%$ and $97.9 \pm 0.7 \%$ were co-expressing $\beta$ III-tubulin, confirming their neuronal identity. Additionally, based on the neural-colony forming cell assay, the shaking method resulted in the generation of a homogenous neuronal cell population without any bona fide NSC contamination.

Conclusions: The shaking purification method allows easy, low cost, efficient and large-scale separation of immature neurons from dNSC progeny, potentially benefiting both basic and clinical applications.

Keywords: Neural stem cell; Differentiation; Neurosphere assay; Neuroblast assay; Immature neuron; Purification; Shaking; Differential attachment

\section{Introduction}

Enriched neuronal cell populations are valuable tools both for basic laboratory investigations and cell therapy applications. Neuronal cells can be harvested from various sources ranging from primary neural tissue of deceased human bodies [1] and aborted fetuses $[2,3]$ to different stem cell populations such as embryonic stem cells (ESCs) [4-6], induced pluripotent stem cells (iPSCs) [7-9], and neural stem cells (NSCs) $[10,11]$. Supply and ethical issues associated with harvesting neuronal cells from primary neural tissue limits their clinical application, although they might greatly benefit laboratory pre-clinical studies. Pluripotent stem cells such as ESCs and iPSCs are promising sources of cells for neuronal cell therapy because of their abilities to differentiate into various neuronal cell subtypes. However, the tumorigenic potential and impurity of the differentiated cell types increase the risks involved in clinical application $[12,13]$.

NSCs represent a viable alternative source of cells that could easily be propagated in vitro and differentiated into the major cell types of the nervous system (i.e. neurons, astrocytes and oligodendrocytes). Nonetheless, NSCs have not yet reached the expected level of clinical application for neuronal cell therapy due to the heterogeneity of in vitro expanded NSC progeny (i.e culture of NSCs contains bona fide NSCs, lineage-restricted neuronal and glial progenitors, and terminally differentiated cells) and the low yield of neurons upon differentiation. Moreover, the presence of a subpopulation of bona fide NSC within the slurry of donor cells may result in undesired growth, which raises concern and the need for more defined populations of cells for transplantation $[14,15]$.

Generating defined neuronal cells from all available cell sources mentioned before usually demands sophisticated methods such as fluorescent activated cell sorting (FACS) or magnetic cell sorting (MACS), together with costly reagents and antibodies that limit the universal accessibility and clinical application of these methodologies.

We previously developed an assay named as the neuroblast assay (NBA) to enrich immature neuronal cells, exploiting the distinct morphological characteristics of glial and neuronal cell populations in differentiating NSC progeny, and could enrich a population of immature neurons solely based on cell size and internal complexity

*Corresponding author: Hassan Azari, Department of Anatomical Sciences,Neural Stem Cell and Regenerative Neuroscience Laboratory, Shiraz University of Medical Sciences, Shiraz, Iran - 7134853185, Tel: +98 9177074513; Fax: +98 711 2304372; E-mail: azari.hassan@gmail.com

Received January 31, 2014; Accepted March 15, 2014; Published March 17 2014

Citation: Azari H, Sharififar S, Darioosh RP, Fortin JM, Rahman M, et al. (2014) Purifying Immature Neurons from Differentiating Neural Stem Cell Progeny Using a Simple Shaking Method. J Stem Cell Res Ther 4: 178. doi:10.4172/21577633.1000178

Copyright: (C) 2014 Azari $\mathrm{H}$, et al. This is an open-access article distributed unde the terms of the Creative Commons Attribution License, which permits unrestricted use, distribution, and reproduction in any medium, provided the original author and source are credited. 
Citation: Azari H, Sharififar S, Darioosh RP, Fortin JM, Rahman M, et al. (2014) Purifying Immature Neurons from Differentiating Neural Stem Cell Progeny Using a Simple Shaking Method. J Stem Cell Res Ther 4: 178. doi:10.4172/2157-7633.1000178

(i.e. forward and side scatter properties; FSC and SSC) [10]. Although an enrichment of more than $75 \%$ was obtained with this approach, combining it with a negative (excluding $\mathrm{O} 4$ and A2B5-immunoreactive (IR) cells) or a positive (selecting the PSA-NCAM-IR cells) selection approach was needed to reach an almost homogenous neuronal cell population (up to $97 \%$ purity). Here, we modified this methodology in such a way that would not need any complicated high technology facility like FACS. In addition, this methodology can be practiced in any laboratory equipped with very basic facilities. Using this approach, we could reach a pure population of neuronal cells from dNSC progeny without any bona fide NSC contamination, which is an advantage for neuron-replacement therapy for neurodegenerative diseases and helps prevent uncontrolled proliferation and possible tumor formation.

\section{Materials and Methods}

\section{Animals}

Wild type $\mathrm{C}^{2} 7-\mathrm{BL}_{6}$ (Harlan Laboratories, Indianapolis, IN, USA) mice (male and female) were housed with unlimited access to food and water as breeding pairs, and time-mated female mice were sacrificed at day 14 of gestation to harvest embryonic brain tissue. The University of Florida Institutional Animal Care and Use Committee (IACUC) approved all experimental protocols in this study (Protocol\#200902545).

\section{Neural stem and progenitor cell isolation and expansion}

Neural stem and progenitor cells from the ganglionic eminences of $\mathrm{E}_{14}$ brains of $\mathrm{C} 57-\mathrm{BL}_{6}$ wild-type mice were isolated and expanded using the neurosphere assay [16]. Briefly, harvested tissue from whole ganglionic eminences were dissociated into single cell suspension and plated at $2 \times 10^{5}$ cells $/ \mathrm{ml}$ in mouse NeuroCult basal NSC Medium plus mouse Neurocult NSC Proliferation Supplements (Stem Cells Technologies, Vancouver, Canada) supplemented with $20 \mathrm{ng} / \mathrm{ml} \mathrm{EGF}$, $10 \mathrm{ng} / \mathrm{ml} \mathrm{bFGF} \mathrm{(R \& D} \mathrm{system,} \mathrm{Minneapolis,} \mathrm{MN,} \mathrm{USA)} \mathrm{and} 2 \mu \mathrm{g} / \mathrm{ml}$ heparin (Sigma) in NUNC tissue culture flasks in humidified $37^{\circ} \mathrm{C}$ incubator with $5 \% \mathrm{CO}_{2}$. To expand neural stem cells, neurospheres were passaged every 5-7 days, depending on their size, using $0.05 \%$ trypsin-EDTA (Gibco, USA) and plated at a density of $5 \times 10^{4}$ cells $/ \mathrm{ml}$ in neurosphere culture medium.

\section{Neural stem and progenitor cell differentiation}

We differentiated NSC progeny based on our recently published methodology known as the neuroblast assay (NBA) $[10,17,18]$. Briefly, neurospheres harvested from passage one to three were dissociated into single cells using $0.05 \%$ trypsin-EDTA (Gibco, USA) and plated at a density of $3 \times 10^{5}$ cells $/ \mathrm{ml}$ in mouse NSC supplemented by $5 \%$ fetal calf serum (FCS) (Gibco), $20 \mathrm{ng} / \mathrm{ml} \mathrm{EGF,} 10 \mathrm{ng} / \mathrm{ml} \mathrm{bFGF}$ and $2 \mu \mathrm{g} /$ $\mathrm{ml}$ heparin (Sigma) for 3-4 days (Proliferation Stage). When the culture became around $90-95 \%$ confluent, the medium was changed to the growth factor free medium containing 5\% FCS so that neuronal progenitor cells could divide and generate clusters of immature neuronal cells (Differentiation Stage) (Figures 1A-1D).

\section{Isolating neuronal cells using the shaking method}

Five days after the differentiation stage (Figure 1E), medium was removed from the NBA culture flask, filtered through $0.2 \mu \mathrm{m}$ filter to remove floating debris and kept in an appropriate size sterile Falcon tube. The NBA cultures were washed with pre-warmed sterile phosphate-buffered saline (PBS) to remove serum from the culture. Pre-warmed $0.05 \%$ trypsin-EDTA was added to each flask just as much to cover the culture with a very thin layer. After 1 minute incubation in a $37^{\circ} \mathrm{C}$ incubator, an equal volume of pre-warmed trypsin inhibitor (prepared as $0.014 \% \mathrm{w} / \mathrm{v}$ trypsin inhibitor (type I-S from soybean; Sigma- Aldrich, St. Louis, MO) in HEPES-buffered minimum essential medium (HEM), which consisted of minimum essential medium (Invitrogen) and $16 \mathrm{mM}$ HEPES (Sigma-Aldrich)) was used to quench trypsin activity. Then, the mixture of trypsin and trypsin inhibitor was removed from the flasks and the original medium from the same flask was put back to the lightly trypsinized culture and the lid of each flask was sealed with parafilm to prevent medium $\mathrm{pH}$ change. The flask was then placed on top of a 2314FS model shaker (Cat. \# 11-402-12, Fisher Scientific, Dubuque, Iowa, USA) and shaken for 30 minutes at $150 \mathrm{rpm}$ in order to detach neuronal cell clusters from the underlying astrocytic monolayer (Figure 1F). The cell suspension was then collected and centrifuged at $1200 \mathrm{rpm}$ for 5 minutes. After resuspending in an appropriate volume of NSC medium, depending on the pellet size, the clusters of immature neuronal cells were gently dissociated into single cells by pipetting the medium up and down. The resulting suspension was passed through a $40 \mu \mathrm{m}$ cell strainer (BD, Falcon, USA) to separate non-dissociated clumps. Cells then were counted using trypan blue and plated at $1-3 \times 10^{4}$ cells/well in 96 well in $250 \mu \mathrm{l}$ of NSC medium with $5 \% \mathrm{FCS}$, with or without $20 \mathrm{ng} / \mathrm{ml}$ of human recombinant BMP4
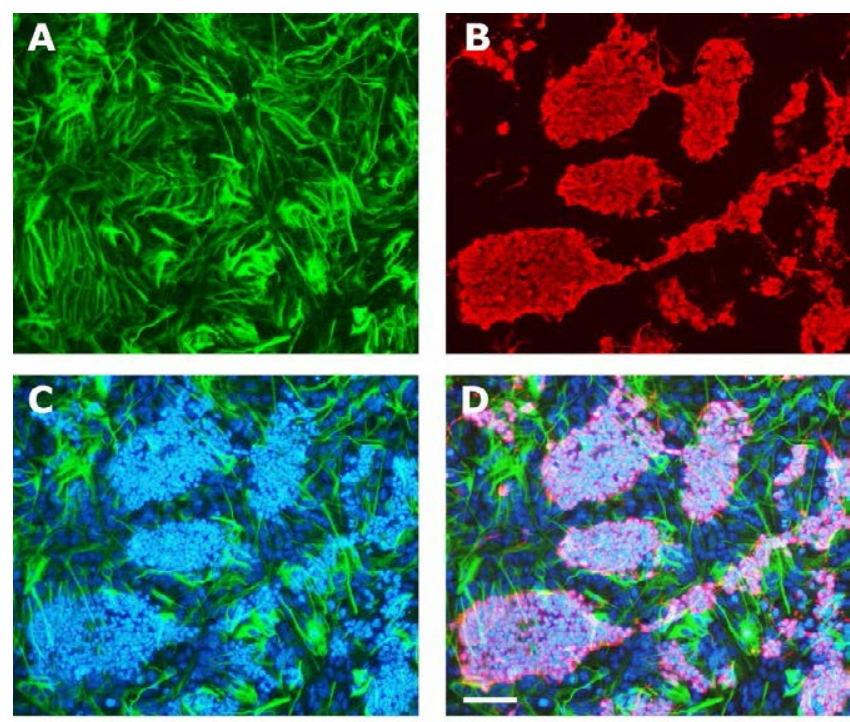

B III-tubulin, GFAP, DAPI
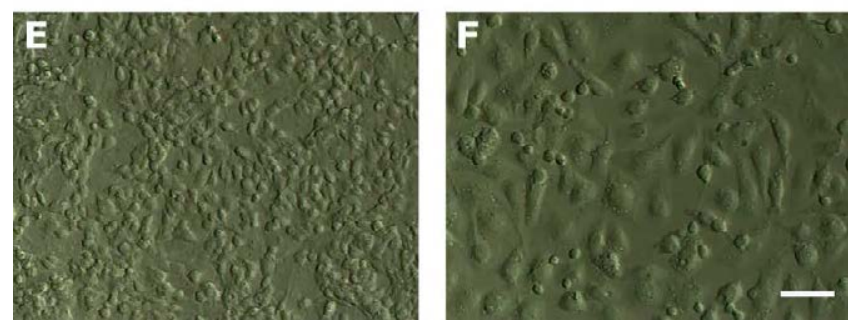

Figure 1: Differentiating neural stem cell progeny and isolating neuronal cells (A-D): Representative micrographs of the neuroblast assay (NBA) culture, 4 days after switching to growth factor free medium and stained for the astrocyte marker; GFAP (A), neuronal marker; $\beta$ III-tubulin (B) and counterstained with DAPI (C). The colonies of $\beta$ III-tubulin positive neuronal cells are on top of the astrocyte monolayer (D). (E-F): The NBA culture before (E) and after $(F)$ shaking. After shaking the majority of the top neuronal cell clusters are detached from the underlying astrocytic cell monolayer. Scale bars $=50 \mu \mathrm{m}$. Abbreviations: GFAP = Glial fibrillary acidic protein, $I R=$ Immunoreactive, $\mathrm{DAPI}=$ 4',6-Diamidino-2-Phenylindole. 
and $25 \mathrm{ng} / \mathrm{ml}$ of human recombinant BDNF (both from R\&D system, Minneapolis, MN, USA).

\section{Isolating neuronal cells based on PSA-NCAM immunoreactivity using MACS}

To purify neuroblast cells we used the isolated superficial neuroblast clusters as described earlier. For this purpose, EasySep PE selection kit (StemCell Technologies) and Phycoerythrin (PE) conjugated anti-PSA-NCAM antibody (Miltenyibiotec, USA) were used based on the manufacturer instructions with some modifications. Briefly, cells (either dissociated NBA cultures or harvested neuronal cells using the shaking method) were resuspended at $5-10 \times 10^{6}$ cells in $100 \mu \mathrm{l}$ of NSC medium in $12 \times 75 \mathrm{~mm}$ polystyrene tube (BD, USA). 10-20 $\mu \mathrm{l}$ of PE conjugated anti-PSA-NCAM antibody was added (final concentration of $0.3-3 \mu \mathrm{g} / \mathrm{ml}$ ) to the cell suspension, mixed gently and incubated for $10 \mathrm{~min}$ in the dark at room temperature. Then, $10 \mu \mathrm{l}$ of EasySep PE Selection Cocktail was added, mixed well and incubated at room temperature for 15 minutes. EasySep Magnetic Nanoparticles were vigorously pipetted up and down to ensure uniform suspension and then $5 \mu$ of these particles were added to the cell suspension and incubated at room temperature for another $10 \mathrm{~min}$. Then, the cell suspension was brought to a total volume of $2.5 \mathrm{ml}$ by adding NSC medium, mixed gently, placed into the EasySep Magnet and set aside for $5 \mathrm{~min}$.

The magnet with the tube was picked up and inverted in one continuous motion to discard the supernatant fraction. The magnet and tube were held in this position for 2-3 seconds and then returned to upright position. The tube was removed and $2.5 \mathrm{ml}$ of NSC medium was added and the suspension was mixed gently, placed back in the magnet and set aside for 5 minutes. This washing step was repeated, for three total times. After the last wash, cells were resuspended in NSC medium, counted and then plated as described before.

\section{Immunofluorescence and microscopy}

To determine the purity of neuronal cells isolated from the differentiating NBA culture using the aforementioned methodologies, plated cells were fixed half an hour after isolation using cold $4 \%$ paraformaldehyde (PFA) and washed with PBS. The primary antibody solution prepared in PBST (PBS $+0.01 \%$ Triton-X) with $10 \%$ normal goat serum (NGS, Sigma-Aldrich) was added to each well of the 96 well plates and incubated for 1 hour at room temperature. Antibodies used in this study are listed in (Table 1). After gentle removal of the primary antibody solutions, the wells were washed with PBS to remove unbounded free antibodies. Then, appropriate secondary antibodies were prepared in PBST (PBS $+0.01 \%$ Triton-X) with $10 \%$ NGS, and were added at $50 \mu \mathrm{l} /$ well and the plate was incubated for $45 \mathrm{~min}$ at room temperature in the dark. Secondary antibodies used in this study included Alexafluor 568 and Alexafluor 488-conjugated goat anti mouse or anti rabbit antibodies (all from Molecular Probes, 1:700). 4'-6'diamidino-2-phenylindole (DAPI) (Molecular Probes, 1:1000) was also added to the secondary antibody solution to label nuclei. Representative pictures of each well (10-15 fields/well) were taken using a fluorescent microscope (Olympus IX-70) equipped with Canon EOS digital camera and cell counts were performed and calculated as a percentage of total cells counted.

Determining neural precursor cell and bona fide NSC frequency in neuronal cells purified by the shaking method

To evaluate sphere forming frequency, isolated neuronal cells were counted and plated in $250 \mu \mathrm{l} /$ well of NSC medium supplemented with
$20 \mathrm{ng} / \mathrm{ml} \mathrm{EGF}$ in 96 well plates (NUNC) at a density of $1 \times 10^{4}$ cells/well. Neurospheres greater than $50 \mu \mathrm{m}$ were counted 7 days after plating and expressed as a percentage of total cells plated.

To evaluate bona fide NSC frequency, isolated neuronal cells were plated at a density of $1 \times 10^{4}$ cells/dish in $35 \mathrm{~mm}$ cell culture dishes (NUNC) in $1.5 \mathrm{ml} /$ dish of serum-free neural colony forming cell assay (N-CFCA) medium containing supplements as described in the Neural Colony Forming Cell Assay kit (Stem Cell Technologies, Vancouver, Canada) [19]. $20 \mathrm{ng} / \mathrm{ml} \mathrm{EGF} \mathrm{was} \mathrm{used} \mathrm{as} \mathrm{a} \mathrm{mitogen.} \mathrm{The} \mathrm{culture} \mathrm{was}$ fed every 7 days with $60 \mu \mathrm{l} /$ dish of the NSC medium with EGF. Twentyone days after plating, colonies were counted, sized, and the number of big colonies (greater than $2 \mathrm{~mm}$ ) was expressed as a percentage of total cells plated representing the frequency of the bona fide neural stem cells [20].

\section{Statistical Analysis}

Results were expressed as the Mean \pm SEM. Using Graphpad Prism 5 software (Prism 5, Graphpad Software Inc. USA); one-way analysis of variance (ANOVA) or student's t-tests were used to analyze data as appropriate. Significant ANOVA values were followed by post hoc comparisons of individual means where applicable. In all comparisons $\mathrm{p}<0.05$ was set as the level of significance.

\section{Results}

\section{Isolating neuronal cells using the shaking method}

Neural stem cells (NSCs) were differentiated based on an established protocol developed in our laboratory named the neuroblast assay (NBA) [10]. Briefly, passaged NSCs were plated at high density in NSC medium containing 5\% FCS, EGF and b-FGF. After reaching 90-95\% confluence, culture medium was replaced with a growth factor free medium. After 4-5 days a double-layered culture appeared with colonies of small $\beta$ III-tubulin IR cells on top of a flat bed of GFAP IR cells (Figures 1A-1D).

Exploiting the double cell layer arrangement of the NBA culture, we briefly trypsinized the culture at day 5 of the differentiation-stage to loosen the attached superficial neuronal cell clusters from the underlying astrocytic monolayer. After applying a gentle shaking force at $150 \mathrm{rpm}$ for 30 minutes on a shaker, superficial neuronal cell clusters were detached (Figures $1 \mathrm{E}$ and $1 \mathrm{~F}$ ) and floating in the culture medium. Half an hour after plating the harvested cells in 96-well plates, dual staining for $\beta$ III-tubulin and GFAP demonstrated that $97.9 \pm 0.6 \%$ of the cells in this population were small, round or spindle-shaped $\beta$ III-tubulin IR cells and $0.6 \pm 0.15 \%$ were large and flat GFAP IR cells (Figures 2A-2E). Further analysis showed that $5.3 \pm 0.4 \%$ of the plated cells were Ki-67 IR, of which $97.9 \pm 0.7 \%$ were double labeled with $\beta$ III-tubulin, showing that the majority of these proliferating cells were dividing neuroblast cells (Figures 3A-3H). Thus, employment of this

\begin{tabular}{|c|c|c|c|}
\hline & Antigen & Working dilution & Source \\
\hline \multirow{4}{*}{ Neurons } & $\begin{array}{c}\text { MIll-tubulin } \\
\text { Microtubule-associated } \\
\text { protein-2 (MAP-2) }\end{array}$ & $1: 2,000$ & Promega\#G7121 \\
\cline { 2 - 4 } & Double cortin & $1: 300$ & Chemicon \# MAB3418 \\
\cline { 2 - 4 } & PSA-NCAM & $1: 300$ & Chemicon \# AB5910 \\
\cline { 2 - 4 } & DARPP-32 & $1: 500$ & Sigma\#AB4503329 \\
\cline { 2 - 4 } & GAD-65/67 & $1: 500$ & Millipore\#AB1511 \\
\hline Astrocytes & $\begin{array}{c}\text { Glial fibrillary acidic } \\
\text { protein (GFAP) }\end{array}$ & $1: 500$ & DakoCytomation \# Z0334 \\
\hline
\end{tabular}

Table 1: Primary antibodies and their targeted antigens. 
Citation: Azari H, Sharififar S, Darioosh RP, Fortin JM, Rahman M, et al. (2014) Purifying Immature Neurons from Differentiating Neural Stem Cell Progeny Using a Simple Shaking Method. J Stem Cell Res Ther 4: 178. doi:10.4172/2157-7633.1000178
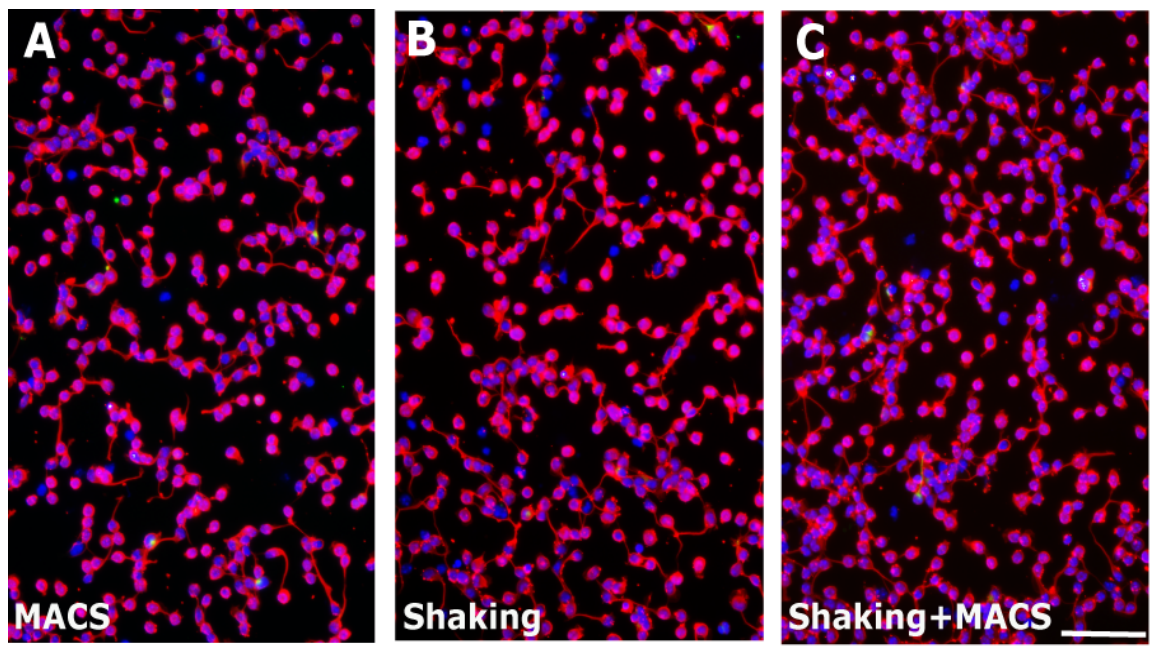

ß III-tubulin, GFAP, DAPI

D

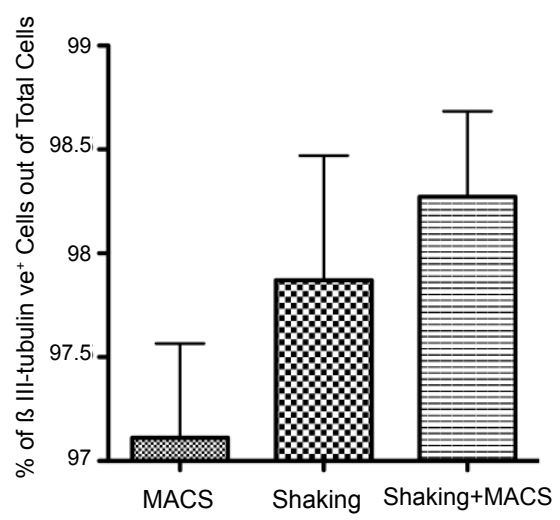

$\mathbf{F}$
E

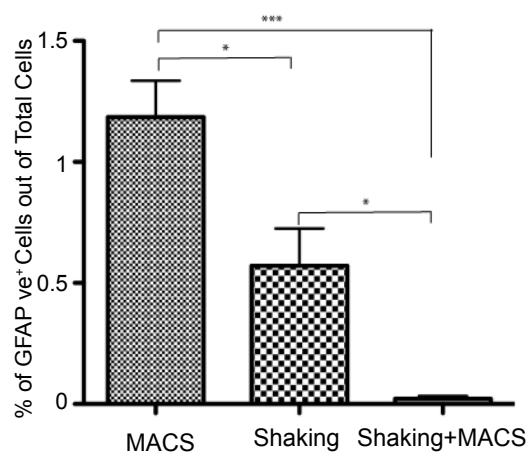

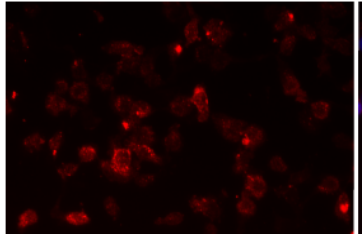

PSA-NCAM, DAPI

Figure 2: Phenotypic analysis of the isolated cells based on different purifying methods.(A-C): Representative micrographs of the isolated cells based on the MACS $(A)$, Shaking $(J)$, and Shaking + MACS (C) purifying methods that were stained (half an hour after plating) for $\beta$ III-tubulin, GFAP and DAPI. (D-E): The percentage of $\beta$ III-tubulin IR (D) and GFAP IR (E) cells was quantified for each of the isolated populations. While the percentage of $\beta$ III-tubulin IR cells did not significantly change using different strategies, compared to the MACS method, both the Shaking and the Shaking + MACS methods significantly resulted in less GFAP IR astrocytes in the isolated cell population (mean \pm SEM; $n=3-5$ independent experiments; ${ }^{*} p<0.05,{ }^{* * *} p<0.0001$, one-way ANOVA). (F): Representative micrographs of the isolated cells based on Shaking purifying method that were stained (half an hour after plating) for PSA-NCAM and DAPI. Scale bars $=50 \mu \mathrm{m}$. Abbreviations: GFAP $=$ Glial fibrillary acidic protein, IR= Immunoreactive, DAPI= 4',6-Diamidino-2-Phenylindole, PSA-NCAM = Polysialylated neuronal cell adhesion molecule, ANOVA= analysis of variances.

strategy allowed an enriched population of immature neurons ( $98 \%$ ) to be separated from astrocytes, based on cells' differential attachment properties to the substrate.

\section{Isolating neuronal cells based on PSA-NCAM immunoreactivity using MACS}

PSA-NCAM is a marker of both the mitotically active neuronal progenitor cells and the early post-mitotic neurons in embryonic neural tube and in chain-migrating neuronal precursors in the subventricular zone (SVZ) of the adult brain [21, 22]. PSA-NCAM was used previously to purify neuronal cells from embryonic rat neural tubes [21], adult mouse SVZ [22], embryonic stem cell derived neuronal cells [23] and immature neuronal cells from dNSC progeny [10]. Using PEconjugated PSA-NCAM antibody and EasySep PE Selection MACS 
Citation: Azari H, Sharififar S, Darioosh RP, Fortin JM, Rahman M, et al. (2014) Purifying Immature Neurons from Differentiating Neural Stem Cell Progeny Using a Simple Shaking Method. J Stem Cell Res Ther 4: 178. doi:10.4172/2157-7633.1000178
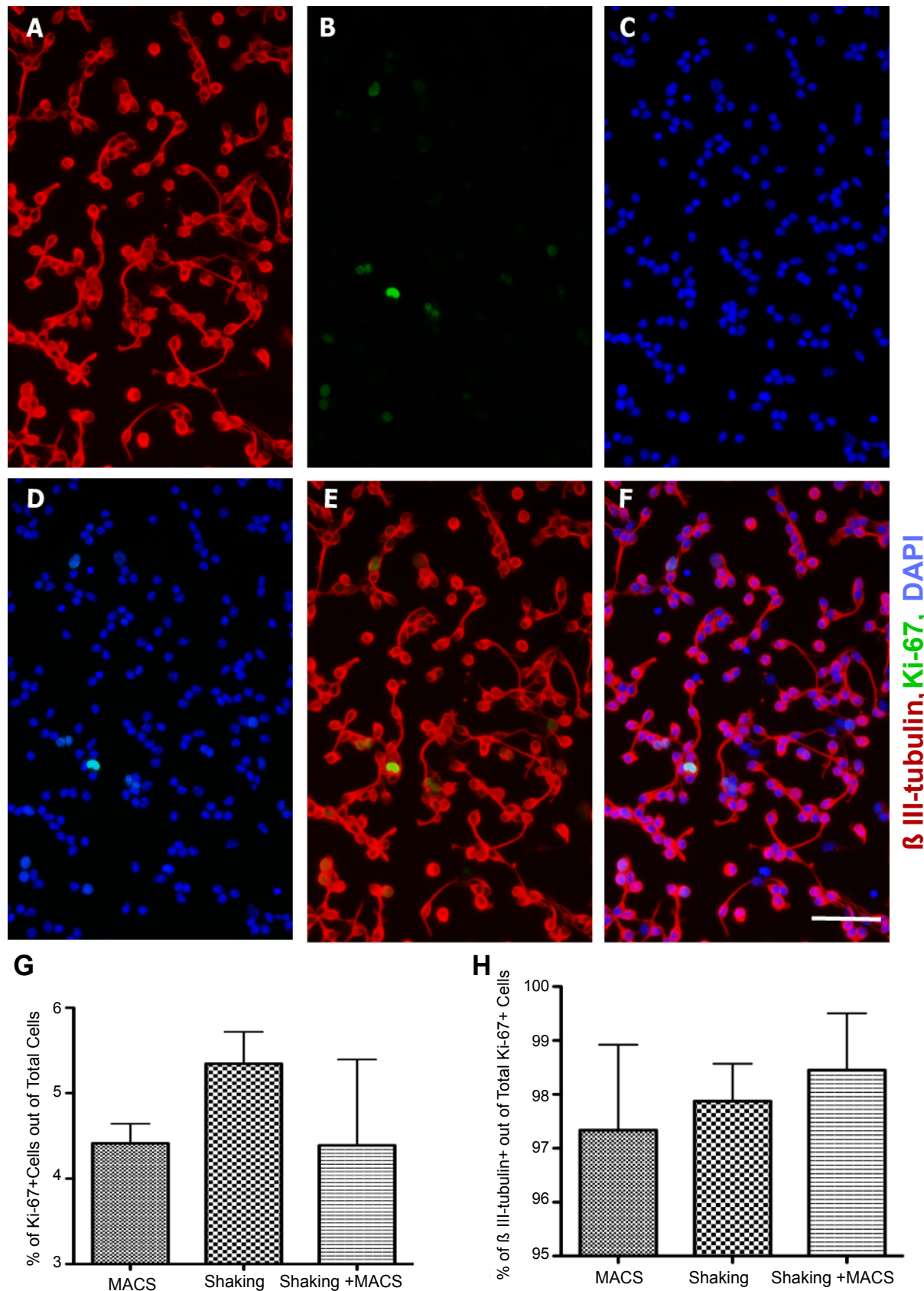

Figure 3: Percentage of Ki-67 dividing cells in the isolated cells based on different purifying methods. (A-F): Representative micrographs of the isolated cells immunostained for neuronal marker; $\beta$ III-tubulin (A), cell proliferation marker; Ki-67 (B), DAPI counterstain (C), DAPI-Ki-67 (D), $\beta$ III-tubulin-Ki-67 (E), and $\beta$ III-tubulin$\mathrm{Ki}-67-\mathrm{DAPI}$ merged (F). (G-H): Comparing the mean percentage of Ki-67 IR cells (G) and $\beta$ III-tubulin co-expressing Ki-67 IR cells (H) in the isolated cell populations based on the MACS, Shaking and Shaking + MACS methods. As evident, the majority of Ki-67 IR cells are expressing $ß$ III-tubulin, confirming their neuronal identity. No significant differences were detected between purifying methods. (mean $\pm \mathrm{SEM} ; \mathrm{n}=3$ independent experiments). Scale bars $=50 \mu \mathrm{m}$. Abbreviations: $\mathrm{GFAP}=\mathrm{Glial}$ fibrillary acidic protein, IR= Immunoreactive, DAPI= 4',6-Diamidino-2-Phenylindole.

kit; we isolated PSA-NCAM IR cells after dissociating the NBA culture into single cell suspension. The purity of $\beta$ III-tubulin IR cells in this approach was $97.1 \pm 0.45 \%$, which was not significantly different from the shaking method. On the other hand, the mean percentage of GFAP IR cells was $1.18 \pm 0.15 \%$, which was significantly higher than the shaking method $(\mathrm{P}<0.05$, Figures $2 \mathrm{~A}-2 \mathrm{E})$. Further immunostaining analysis showed that $4.41 \pm 0.23 \%$ of the isolated cell population were actively dividing Ki- 67 IR cells, of which $97.34 \pm 1.6$ were $\beta$ III-tubulin expressing neuronal cells (Figures 3A-3H).

\section{Further purifying the shaking-based isolated neuronal cells using MACS}

Immunofluorescence analysis on the purified neuronal cells isolated using the shaking method showed that $84.9 \pm 1.3 \%$ of these cells expressed PSA-NCAM (Figure 2F). While purification based on the shaking method resulted in a highly purified neuronal population, we used the PE-conjugated PSA-NCAM antibody and EasySep PE Selection MACS kit to further increase the purity of the isolated 
neurons. Using this combined approach, the purity of $\beta$ III-tubulin IR cells was $98.3 \pm 0.4 \%$ with no statistically significant difference to the shaking alone method (Figures $2 \mathrm{C}-2 \mathrm{E}$ ). In contrast, the mean percentage of GFAP IR cells was significantly decreased from $0.6 \pm$ $0.15 \%$ in shaking alone to $0.02 \pm 0.01 \%$ using the combined approach $(\mathrm{P}<0.05$, Figures $2 \mathrm{C}$ and $2 \mathrm{E})$. Moreover, the mean percentage of $\mathrm{Ki}-67$ IR dividing cells were decreased from $5.3 \pm 0.4 \%$ in shaking alone to 4.4 $\pm 1 \%$ using the combined approach (Figures $3 \mathrm{G}$ and $3 \mathrm{H}$ ) but this value was not statistically significant. Double labeling with $\beta$ III-tubulin revealed that $98.4 \pm 1 \%$ of the Ki-67 IR cells were dividing neuroblast cells (Figure $3 \mathrm{H}$ ).

\section{Neural precursor cell and bona fide NSC frequency in purified neuronal cells using the shaking method}

As stated earlier, $5.3 \pm 0.4 \%$ of the isolated cells obtained from the shaking method were Ki-67 IR proliferating cells, of which the vast majority were $\beta$ III-tubulin IR neuronal cells. While the potential for uncontrolled proliferation and tumor formation following transplantation of NSC progeny is low, the risk is still present $[14,15,24]$. To ensure safety in using this method to purify neuronal cells for implantation purposes, we also determined the precursor and stem cell frequency in the isolated cell population employing two assays: (1) The Neurosphere Assay (NSA), which provides a readout of precursor cells (including both stem and progenitor cells) and (2) The Neural-Colony Forming Cell Assay (N-CFCA) enabling quantitative discrimination between stem and progenitor cells [20]. Briefly, isolated cells using the shaking method were cultured in the NSA and the N-CFCA for 7- and 21-days, respectively. In the NSA the number of spheres were counted (Figure 4A), and the total number colonies, including large colonies ( $>2 \mathrm{~mm}$ in diameter), were enumerated in the N-CFCA (Figures $4 \mathrm{~B}$ and $4 \mathrm{C}$ ). Within the isolated cell population, sphere-forming frequency was $0.09 \pm 0.004 \%$ and colony-forming frequency was $0.097 \pm 0.0054$ (Figure 4D). Surprisingly, we could not detect any colonies larger than $2 \mathrm{~mm}$, which would have represented bona fide stem cells.

\section{Discussion}

In this study, we took advantage of differential substrate attachment properties of neuronal and glial cells in a differentiating NSC (dNSC) progeny culture. In dNSC progeny culture, neuronal cells comprise clusters of cells overlying a monolayer of mainly astrocytic cells (Figures 1A-1D). We developed a simple shaking method that after a brief trypsinization to detach the top neuronal cell clusters facilitated easy and efficient isolation of these cells from the rest of the dNSC progeny, without need for the high cost and complex technologies such as MACS and FACS. The isolated neuronal cell population could survive in vitro and fully differentiate into DARPP-32 expressing GABAergic neurons (Figure 4E) as shown in our previous study [10]. These cells could potentially serve as an excellent cell source for therapeutic applications in Huntington's disease, where DARPP-32 expressing GABAergic medium spiny neurons are lost in the neostriatum and cortex [25].

The shaking method resulted in isolation of a homogenous neuronal cell population from dNSC progeny, comparable to the level of purity achieved by the parallel MACS method used in this study. While the percentages of astrocytes were negligible in both purifying methods, the shaking method resulted in less astrocytic contamination of the purified neuronal cells as compared to the parallel MACS method. In addition, the purity achieved by the shaking method was comparable to what was gained employing PSA-NCAM immunopanning and MACS methods to isolate neuronal cells from differentiating ESCs $[23,26]$. In MACS based isolation the resulting cellular purity and yield are greatly affected by sample preparation process and especially the immunostaining. Application of incorrect antibody concentration in the staining solution or insufficient washing following staining may result in poor yield and/or purity. Inadequate washing or using inadequate amount of antibody will result in poor purity, whereas using too much antibody will result in poor yield [27]. However, the shaking method requires a brief treatment $(1 \mathrm{~min})$ with mild trypsinEDTA $(0.05 \%)$ without the need for any immunostaining process. MACS purification of the isolated neuronal cells obtained from the shaking method increased the purity of $\beta$ III-tubulin IR cells (around $0.5 \%)$ and decreased the percentage of GFAP IR contaminant cells (around $0.58 \%$ ). Although the decrease in the percentage of GFAP IR contaminant cells was statistically significant, it is not important when considering the cost, complexity and the length of the purification process and the potential damages to the health and quality of the obtained cells. Thus, the shaking method is preferred because millions of neuronal cells could be efficiently isolated within an average of 30 min without the need for any costly antibody and cell separation facilities.

The purity of the isolated neurons using the shaking method was comparable to the purity level (96\%) achieved by Sandra Pennartz et al. [22] using the FACS method to sort PSA-NCAM positive cells from digested tissue harvested from the subventicular zone of the adult mouse brain. However, using the FACS method and sorting neuronal cells from dNSC progeny based on cell size and internal complexity, we achieved a neuronal cell population with a purity of 75\% [10]. Neuronal cell purity increased to more than $97 \%$ when PSA-NCAM positive cells were sorted, which is comparable to the purity of neuronal cells achieved using the shaking method developed in this study. While isolating cells using FACS is beneficial and sometimes inevitable, the limited availability of this costly and complex technology, as well as the need for hiring highly trained operators capable of efficient cell sorting, and also the lengthy process for cell separation, all prevent its use by many investigators. Besides, during FACS isolation, cells are exposed to a pressurized fluid while passing through the flowcytometer that might have adverse effects on their health. Moreover, an inverse correlation exists between the final cellular yield, purity, health and the sort rate [27]. To ensure harvesting sufficient number of highly purified healthy cells, the sorting rate should not exceed a certain event/second threshold depending of the type of FACS machine used. In contrast, the shaking method is time-efficient, very robust and simple and can be operated in a closed system. For example, while the FACS method takes few hours to sort $40 \times 10^{6}$ neuronal cells, using the shaking method takes only $30 \mathrm{~min}$ to achieve the same number of cells.

The neuronal cell population isolated based on the shaking method contained 5\% Ki-67 IR proliferating cells of which $4.9 \%$ were $\beta$ IIItubulin IR, confirming their neuronal identity. The remaining $0.1 \%$ most likely represents other precursor cells, including progenitors and bona fide stem cells. To further dissect the real identity of the remaining $0.1 \%$ proliferating cells we employed the neurosphere assay (NSA) and neural colony forming cell assay (N-CFCA) that enumerate precursor (both stem and progenitor) cells and bona fide NSCs in a given heterogenous cell population, respectively [20]. Our results demonstrated that the neuronal cell population isolated based on the shaking method contained a precursor population (based on the NSA) of approximately 1:1000 cells, which is comparable to the 1:1111 precursor cell frequency in the cell population isolated using the FACS method in our previous study [10]. Surprisingly, the frequency of the bona fide stem cell population (based on the N-CFCA) was reduced from 1:200,000 in neuronal cells isolated based on the FACS method to 
Citation: Azari H, Sharififar S, Darioosh RP, Fortin JM, Rahman M, et al. (2014) Purifying Immature Neurons from Differentiating Neural Stem Cell Progeny Using a Simple Shaking Method. J Stem Cell Res Ther 4: 178. doi:10.4172/2157-7633.1000178
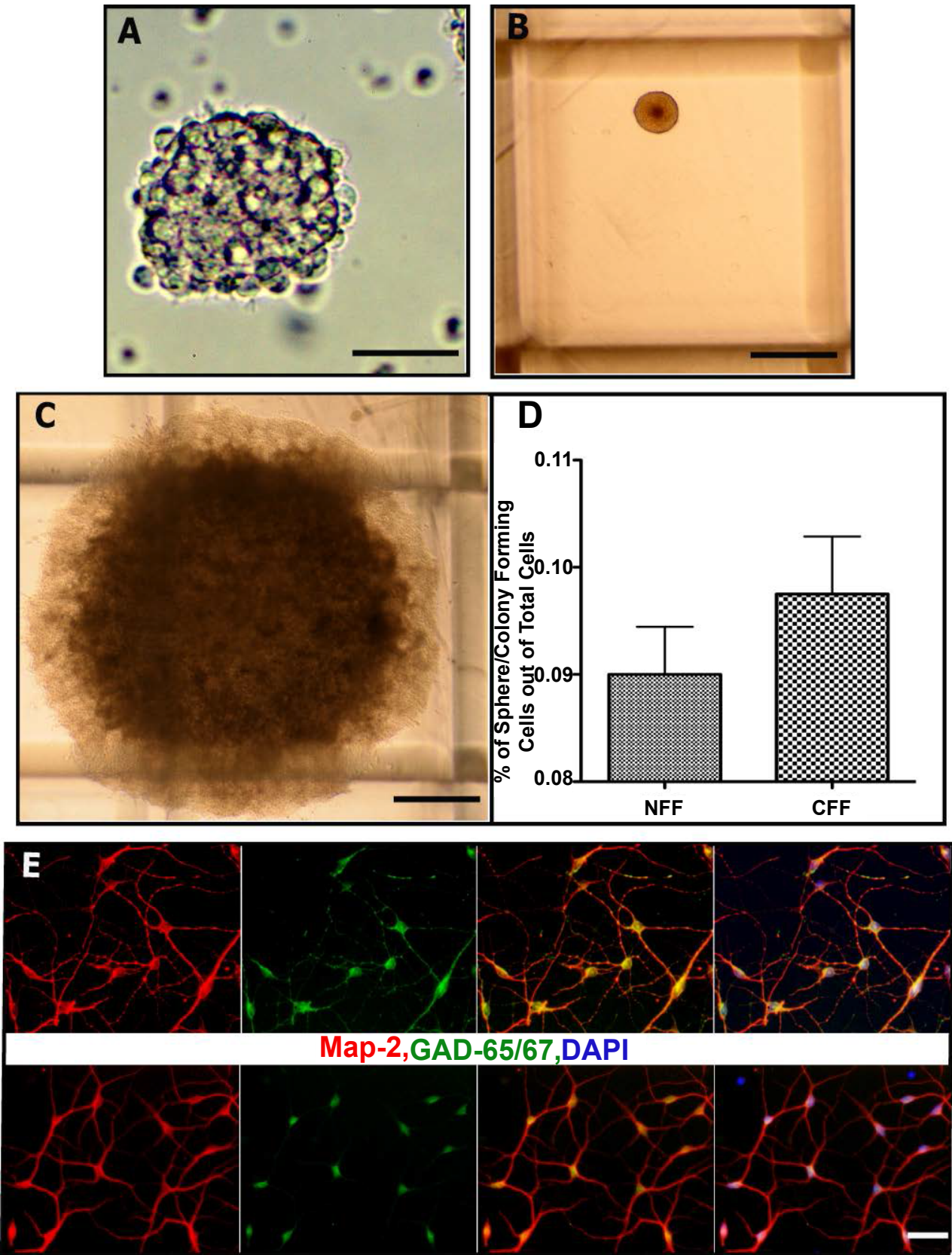

\section{Map-2,GARPP-32, DAPI}

Figure 4: Frequency of stem and progenitor cells, using the NSA and N-CFCA, among the cells isolated by the shaking method, as well as immunophenotyping of the isolated neurons. (A): Representative sphere from isolated cells, 7 days after plating in the NSA culture. (B, C): Typical small and large ( $>2.0 \mathrm{~mm}$ ) colonies that are respectively derived from a neural progenitor cell and a bona fide NSC, 21 days after plating in the N-CFCA. (D): The mean sphere forming frequency in the NSA (C) and the mean colony forming frequency in in the N-CFCA of the cells isolated based on the shaking method. No large colonies (> $2 \mathrm{~mm}$ ) (D) were formed by the cells isolated based on the shaking method and the colonies could only reach to a maximum size of $500 \mu \mathrm{m}(\mathrm{B})$. (mean $\pm \mathrm{SEM}$; $\mathrm{n}=4$ independent experiments). $(E)$ : Representative micrographs from differentiated purified neuronal cells 7 days after plating. Isolated neuronal cells were terminally differentiated in astrocyte conditioned medium supplemented with $20 \mathrm{ng} / \mathrm{ml}$ of BMP-4 and $20 \mathrm{ng} / \mathrm{ml}$ of BDNF and almost exclusively all of the MAP-2 IR cells were expressing GAD $65 / 67$ and DARPP-32 after 7 days. Scale bars $=50 \mu \mathrm{m}$ for $A$ and $E$, and $500 \mu \mathrm{m}$ for B and C. Abbreviations: NSA= Neurosphere assay, N-CFCA= neural- colony forming cell assay, BMP-4= Bone morphogentic protein-4, BDNF= Brain derived neurotrophic factor, GAD 65/67= Glutamic acid decarboxylase 65/67, DARPP-32= Dopamin and cAMP regulated phosphoprotein-32, Map-2= Microtubule associated protein-2.

zero in cells isolated based on the shaking method.This could be due to astrocytic nature of the bona fide NSCs and their association with the astrocyte monolayer that has a stronger attachment to the culture dish substrate. We also showed in our previous study that the majority of the bona fide NSCs were accompanying the astrocytic cell population when sorting based on cell size and internal complexity [10]. This elimination of bona fide NSCs is an advantage for neuron-replacement therapy for neurodegenerative diseases, preventing uncontrolled proliferation and possible tumor formation upon transplantation as shown by other studies $[14,15,24]$. 
Citation: Azari H, Sharififar S, Darioosh RP, Fortin JM, Rahman M, et al. (2014) Purifying Immature Neurons from Differentiating Neural Stem Cell Progeny Using a Simple Shaking Method. J Stem Cell Res Ther 4: 178. doi:10.4172/2157-7633.1000178

Page 8 of 8

In conclusion, shaking purification method allows easy, low cost, efficient and large-scale separation of immature neurons from dNSC progeny that may benefit both basic and clinical applications. Using defined cell populations with a known ratio of the key cellular elements reduces variability in pre-clinical and clinical investigations. Defined neuronal cell populations also act as valuable tools for basic laboratory investigations such as in vitro drug screenings, neurotoxicology and screening assays to uncover agents that promote their survival, differentiation, neurite outgrowth and integration into the pre- existing circuitry of the adult CNS.

\section{Acknowledgements}

The Overstreet Foundation (B.A.R) and grant \# 87-4160 from the Shiraz University of Medical Sciences (HA) supported this study.

\section{References}

1. Belkadi AM, Gény C, Naimi S, Jeny R, Peschanski M, et al. (1997) Maturation of fetal human neural xenografts in the adult rat brain. Exp Neurol 144: 369380. [PubMed]

2. Rozental R, Gebhard D, Padin C, Urban M, Wu JY, et al. (1995) Purification of cell populations from human fetal brain using flow cytometric techniques. Brain Res Dev Brain Res 85: 161-170. [PubMed]

3. Freeman TB, Cicchetti F, Hauser RA, Deacon TW, Li XJ, et al. (2000) Transplanted fetal striatum in Huntington's disease: phenotypic development and lack of pathology. Proc Natl Acad Sci U S A 97: 13877-13882. [PubMed]

4. Morizane A, Takahashi J, Shinoyama M, Ideguchi M, Takagi Y, et al. (2006) Generation of graftable dopaminergic neuron progenitors from mouse ES cells by a combination of coculture and neurosphere methods. J Neurosci Res 83 : 1015-1027. [PubMed]

5. Roy NS, Cleren C, Singh SK, Yang L, Beal MF, et al. (2006) Functional engraftment of human ES cell-derived dopaminergic neurons enriched by coculture with telomerase-immortalized midbrain astrocytes. Nat Med 12: 1259-1268. [PubMed]

6. Drury-Stewart D, Song M, Mohamad O, Guo Y, Gu X, et al. (2013) Highly efficient differentiation of neural precursors from human embryonic stem cells and benefits of transplantation after ischemic stroke in mice. Stem Cell Res Ther 4: 93. [PubMed]

7. Karumbayaram S, Novitch BG, Patterson M, Umbach JA, Richter L, et al. (2009) Directed differentiation of human-induced pluripotent stem cells generates active motor neurons. Stem Cells 27: 806-811. [PubMed]

8. Swistowski A, Peng J, Liu Q, Mali P, Rao MS, et al. (2010) Efficient generation of functional dopaminergic neurons from human induced pluripotent stem cells under defined conditions. Stem Cells 28: 1893-1904. [PubMed]

9. Yan Y, Shin S, Jha BS, Liu Q, Sheng J, et al. (2013) Efficient and rapid derivation of primitive neural stem cells and generation of brain subtype neurons from human pluripotent stem cells. Stem Cells Transl Med 2: 862-870. [PubMed]

10. Azari H, Osborne GW, Yasuda T, Golmohammadi MG, Rahman M, et al. (2011) Purification of immature neuronal cells from neural stem cell progeny. PLoS One 6: e20941. [PubMed]

11. Xiong Z, Zhao S, Mao X, Lu X, He G, et al. (2014) Selective neuronal differentiation of neural stem cells induced by nanosecond microplasma agitation. Stem Cell Res 12: 387-399. [PubMed]

12. Chung S, Shin BS, Hedlund E, Pruszak J, Ferree A, et al. (2006) Genetic selection of sox1GFP-expressing neural precursors removes residual tumorigenic pluripotent stem cells and attenuates tumor formation after transplantation. J Neurochem 97: 1467-1480. [PubMed]

13. Miura K, Okada Y, Aoi T, Okada A, Takahashi K, et al. (2009) Variation in the safety of induced pluripotent stem cell lines. Nat Biotechnol 27: 743-745. [PubMed]

14. Yan J, Xu L, Welsh AM, Hatfield G, Hazel T, et al. (2007) Extensive neuronal differentiation of human neural stem cell grafts in adult rat spinal cord. PLoS Med 4: e39. [PubMed]

15. Amariglio N, Hirshberg A, Scheithauer BW, Cohen $\mathrm{Y}$, Loewenthal R, et al (2009) Donor-derived brain tumor following neural stem cell transplantation in an ataxia telangiectasia patient. PLoS Med 6: e1000029. [PubMed]

16. Azari H, Sharififar S, Rahman M, Ansari S, Reynolds BA (2011) Establishing embryonic mouse neural stem cell culture using the neurosphere assay. J Vis Exp. [PubMed]

17. Azari $H$ (2013) Isolation and enrichment of defined neural cell populations from heterogeneous neural stem cell progeny. Methods Mol Biol 1059: 95-106. [PubMed]

18. Azari H, Sharififar S, Fortin JM, Reynolds BA (2012) The neuroblast assay: an assay for the generation and enrichment of neuronal progenitor cells from differentiating neural stem cell progeny using flow cytometry. J Vis Exp. [PubMed]

19. Azari H, Louis SA, Sharififar S, Vedam-Mai V, Reynolds BA (2011) Neuralcolony forming cell assay: an assay to discriminate bona fide neural stem cells from neural progenitor cells. J Vis Exp. [PubMed]

20. Louis SA, Rietze RL, Deleyrolle L, Wagey RE, Thomas TE, et al. (2008) Enumeration of neural stem and progenitor cells in the neural colony-forming cell assay. Stem Cells 26: 988-996. [PubMed]

21. Mayer-Proschel M, Kalyani AJ, Mujtaba T, Rao MS (1997) Isolation of lineagerestricted neuronal precursors from multipotent neuroepithelial stem cells. Neuron 19: 773-785. [PubMed]

22. Pennartz S, Belvindrah R, Tomiuk S, Zimmer C, Hofmann K, et al. (2004) Purification of neuronal precursors from the adult mouse brain: comprehensive gene expression analysis provides new insights into the control of cell migration, differentiation, and homeostasis. Mol Cell Neurosci 25: 692-706. [PubMed]

23. Schmandt T, Meents E, Gossrau G, Gornik V, Okabe S, et al. (2005) Highpurity lineage selection of embryonic stem cell-derived neurons. Stem Cells Dev 14: 55-64. [PubMed]

24. Keene CD, Chang RC, Leverenz JB, Kopyov O, Perlman S, et al. (2009) A patient with Huntington's disease and long-surviving fetal neural transplants that developed mass lesions. Acta Neuropathol 117: 329-338. [PubMed]

25. Guo Z, Rudow G, Pletnikova O, Codispoti K E, Orr B A, et al. (2012) Striatal neuronal loss correlates with clinical motor impairment in Huntington's disease. Mov Disord 27: 1379-1386. [PubMed]

26. Barral S, Ecklebe J, Tomiuk S, Tiveron M C, Desoeuvre A, et al. (2013) Efficient neuronal in vitro and in vivo differentiation after immunomagnetic purification of mESC derived neuronal precursors. Stem Cell Res 10: 133-146 [PubMed]

27. Cato MH, Yau IW, Rickert RC (2011) Magnetic-based purification of untouched mouse germinal center $B$ cells for ex vivo manipulation and biochemical analysis. Nat Protoc 6: 953-960 [PubMed] 